\title{
Redes organizacionais como alternativa para gestão hospitalar: o Sindicato dos Hospitais Beneficentes, Religiosos e Filantrópicos do Vale do Rio Pardo (SINDHVARP)
}

Vanderlei Trindade da Fontoura ${ }^{1}$ Silvio Cezar Arend ${ }^{2}$

\begin{abstract}
Resumo
Os hospitais nasceram do nobre espírito de cuidar dos que necessitavam, há séculos desempenham a missão de ser solução em saúde curativa e preventiva para suas cidades e região. Por sua importância, seus prejuízos operacionais têm sido financiados com muitas dificuldades e, especialmente com a evolução tecnológica, tornaram-se pesadas estruturas, complexas e com custos elevados. Este estudo se propôs, através de uma revisão da literatura e entrevistas com os gestores hospitalares, a compreender parte da realidade institucional dos Hospitais Filantrópicos e Comunitários, como essas organizações interagem com a sua região, seus desafios e seus ativos relacionais, especialmente os integrantes do Sindicato dos Hospitais Beneficentes, Religiosos e Filantrópicos do Vale do Rio Pardo (SINDHVARP). O objetivo foi identificar os principais benefícios do Sindicato como um modelo de rede, na sustentabilidade das organizações e no desenvolvimento da assistência à população, bem como os benefícios das redes organizacionais, através dos seus preceitos teóricos e na visão de seus principais executivos. Os resultados revelam que, isoladamente, as organizações lutam fragilizadas para cumprir sua missão e pouco integram forças que precisariam ser compartilhadas para vencer suas maiores adversidades. Também é proposta uma metodologia de financiamento da atividade hospitalar, com valores fixos e por região, para futuros estudos, que também fortaleçam os elos regionais entre as instituições, com a rede básica utilizando a pesquisa e a prevenção como estratégia principal.
\end{abstract}

Palavras-chave: Regionalização. Desenvolvimento regional. Redes de hospitais. Gestão hospitalar.

\begin{abstract}
Hospitals were born of the noble spirit of caring for those who needed, perform the mission for centuries to be a solution in curative and preventive health care to their cities and regions. Given its importance, its losses have been funded with many difficulties, especially with technological developments; have become heavy structures, complex and costly. This study was through a literature review and interviews with hospital managers, understand the reality of institutional Philanthropic and Community Hospitals, how these organizations interact with their region, its challenges and its relational assets, especially the members of the Syndicate of Hospitals charitable, Religious and charitable Vale do Rio Pardo. The objective was to identify the main benefits of the Union as a network model, the sustainability of organizations and development assistance to the population as well as the benefits of organizational networks, through its theoretical precepts and vision of its key executives. The results show that organizations are struggling alone to fulfill its mission fragile

${ }_{1}^{1}$ Administrador hospitalar. Mestre em Desenvolvimento Regional. vanderlei@hcb.com.br.

2 Doutor em Economia e docente do Programa de Pós-Graduação em Desenvolvimento Regional (PPGDR/UNISC).silvio@unisc.br.
\end{abstract}


and poorly integrated forces that need to be shared, to win his greatest adversity. Also proposed is a method of funding hospital activity with fixed values and by region for future studies, which also strengthen the links between the regional institutions, with the core network using research and prevention as a primary strategy.

Keywords: Regionalization. Regional development. Networks of hospitals. Hospital management.

\section{Introdução}

Segundo o Ministério da Saúde (BRASIL, 2001), o hospital é uma instituição fundamental, pois provê o cuidado com a saúde da sociedade, monitorando o nascimento, a enfermidade e a morte. Estas instituições são marcadas pela complexidade, tendo em vista a magnitude do seu papel na sociedade e as inúmeras responsabilidades que lhes são atribuídas. Mirshawka (1994) define o hospital como parte integrante de uma organização médica e social, cuja função básica consiste em proporcionar à população a assistência médica integral, curativa e preventiva, sob quaisquer regimes de atendimento, inclusive o domiciliar, constituindo-se também um centro de educação, com capacidade de recursos humanos e de pesquisas em saúde.

Os serviços hospitalares estão permanentemente em transformação; à medida que a ciência evolui, os gestores são desafiados a prover meios para disponibilizar novos benefícios. Os usuários mais exigentes não se contentam com qualquer tipo de atendimento, não basta apenas tratar a doença, é preciso meios adequados para tratar bem o doente, o que exige aperfeiçoamento contínuo dos seus recursos humanos, tecnológicos e instalações (LONDOÑO; MORENO; LAVERDE, 2003).

O poder público, com a responsabilidade constitucional de articular políticas públicas que sejam capazes de minimizar as carências de atenção preventiva e curativa da saúde, tem o desafio de administrar um orçamento insuficiente para o custeio das necessidades de investimento. O novo desenho político-institucional dá ênfase à descentralização político-administrativa dos serviços para os municípios com a regionalização e hierarquização da rede de serviços de saúde e a participação através dos Conselhos de Saúde (CARVALHO, 1999).

O Sistema Único de Saúde (SUS) propõe a saúde de forma integral, ou seja, difere do modelo anterior, que dissociava as ações preventivas das ações curativas. Este modelo vincula a saúde à implementação de políticas sociais e econômicas, que visem à redução do risco de doenças e outros agravos. A universalização do acesso deve ser estabelecida em todos os níveis de assistência.

Embora o SUS estabeleça a universalidade no atendimento aos usuários do sistema, o acesso é demorado e com diversas deficiências, especialmente se o analisarmos no âmbito regional. Um aspecto muito importante que deu origem ao recorte de pesquisa é o caráter isolado de atuação das organizações hospitalares do Vale do Rio Pardo, contrapondo as premissas públicas de atuação em redes ou que habitualmente são utilizadas em países como Inglaterra, Canadá, etc. O Estado, Conselho Regional de Desenvolvimento - COREDE e o Sindicato, quando se referem aos hospitais da região do Vale do Rio Pardo, reportam-se a grupos diferentes de hospitais, embora todos estejam 
fazendo referência à mesma unidade territorial. Esta falta de continuidade confunde as referências assistenciais, dificulta a formação de redes, enfraquece os vínculos institucionais e provoca excessos de investimentos, devido à concorrência que acaba ocorrendo entre as organizações.

Santos (1999), quando se refere ao desenvolvimento na perspectiva territorial, coloca que devemos estar atentos ao território como um todo, compreender a sua dinâmica e a sua diversidade e, a partir daí, analisarmos as possíveis estratégias de promoção de desenvolvimento regional sustentável. Nesse sentido, o sindicato dos hospitais representa uma expressão de sua territorialidade, na qual as organizações começam a fortalecer seus vínculos institucionais na tentativa de encontrar alternativas para ter mais força em suas reivindicações junto ao Estado, convênios, etc. Estas inter-relações propiciam a socialização de informações para discutirem dificuldades e acharem alternativas.

Os hospitais do Vale do Rio Pardo possuem 1.300 leitos aproximadamente, sendo que desse total normalmente $60 \%$ são oferecidos para o SUS, pois todos são hospitais filantrópicos, ou seja, sem fins lucrativos (BRASIL, 2001). O desenvolvimento destas organizações é a garantia de que seus munícipes não precisarão deslocar-se aos grandes centros em busca de atendimento, o que seria extremamente difícil para a maioria dos pacientes, especialmente os de baixa renda.

Embora a responsabilidade constitucional de oferecer atendimento médico de qualidade e zelar pela saúde de todos seja do setor público, este não consegue atender a todos indistintamente (PAIM; ALMEIDA, 2000). As organizações hospitalares, especialmente as filantrópicas, tentam, dentro de sua missão, minimizar essa deficiência. $O$ problema é que a necessidade é maior que as possibilidades nos atendimentos de suas comunidades e região. Segundo Teixeira (2008), o Brasil possui uma legislação de primeiro mundo no tocante à saúde. Contudo, seu orçamento financeiro é de terceiro mundo, o que provoca os intermináveis conflitos entre governantes e gestores hospitalares. Os hospitais filantrópicos, cumprindo as normas da filantropia, disponibilizam $60 \%$ dos seus serviços para o SUS e buscam, com o restante da sua capacidade instalada, suprir o déficit financeiro do atendimento SUS e adequar-se às exigências do mercado.

A realidade da atividade hospitalar não é um tema que seja atrativo para boa parte das pessoas, mas problemas de saúde são realidades com as quais, em vários momentos, nos defrontamos, momentos em que se depende de uma estrutura de tratamento curativo. Para esses momentos, imagina-se que existirá um local pronto para o atendimento, com os melhores profissionais, a mais avançada das tecnologias, com total disposição para contribuir com a nossa recuperação física. No momento de total vulnerabilidade e dependência de pessoas estranhas, descobrem-se as falhas do sistema de saúde e a fragilidade das instituições no atendimento às nossas expectativas, deficiências que podem ser decisivas no salvamento de vidas (RIVERA, 2003).

Assim, o presente estudo aborda a dinâmica de redes hospitalares e as práticas utilizadas pelos gestores da saúde no Vale do Rio Pardo. O objetivo principal é identificar aspectos estratégicos da gestão hospitalar, envolvendo a regionalização, os benefícios das redes organizacionais na gestão, especialmente com o Sindicato dos Hospitais Beneficentes, Religiosos e Filantrópicos do Vale do Rio Pardo (SINDHVARP). A metodologia utilizada baseou-se em revisão bibliográfica e entrevistas abertas (YIN, 2001). 


\section{Organizações hospitalares}

Segundo Machado (1978), as organizações hospitalares tiveram sua origem no espírito de segregar a presença incômoda dos doentes, retirar do convívio aquelas pessoas que provocavam desconforto na sociedade. Esta história, a cada tempo, localidade, apresenta evoluções diferentes, de acordo com as peculiaridades locais e regionais.

A origem e a história dos hospitais apresentam divergências quanto às formas de constituição, seus fundadores e benfeitores. Foi o momento em que cada comunidade sentiu a necessidade de ter o seu próprio hospital e soube articular o meio para tê-lo. O surgimento dos hospitais é uma parte coadjuvante no processo de desenvolvimento dos povos e das comunidades, que objetivavam a melhoria da qualidade de vida de sua população. Foram as alternativas possíveis para enfrentar as doenças que afetaram a humanidade, ao longo da história, com soluções profissionais ou leigas, que buscavam práticas ou técnicas que minimizassem os sofrimentos de seus doentes e a cura de seus males (ANTUNES, 1991).

Para Cherubin e Santos (1997), com o aperfeiçoamento hospitalar, o homem descobriu também que o estado de saúde do indivíduo é um dos elementos primordiais para sua plena realização, oferecendo mais segurança no momento do nascimento, assim como contribuindo para o aumento sempre maior da expectativa de vida. A trajetória dos hospitais assumiu contornos muito mais aperfeiçoados quando os povos reconheceram que sua existência na comunidade era um direito inerente à cidadania do indivíduo e um dever do Estado.

O conceito mais contemporâneo de hospital decorre da própria definição de saúde que o hospital procura manter como sua finalidade primeira. O Ministério da Saúde conceitua as organizações hospitalares como aquelas que têm por base a ação de um serviço médico - ambulatório, postos de assistência geral - prestado pelos hospitais gerais e especializados. Também as define como parte integrante de uma organização médica integral, curativa e preventiva, sob quaisquer regimes de atendimento, inclusive o domiciliar, como centro de educação, capacidade de formar recursos humanos e de pesquisas em saúde, bem como de encaminhamento de pacientes, cabendo-lhes supervisionar e orientar os estabelecimentos de saúde a eles vinculados.

De acordo com o Decreto no 37.773/1955 (BRASIL, 2010), ficou definido na lei Orgânica da Assistência Médico-Hospitalar que "Hospital é a instituição destinada a internar, para diagnóstico e tratamento, pessoas que necessitem de Assistência Médica e cuidados constantes de enfermagem". A organização Mundial da Saúde (OMS), em seu relatório $\mathrm{n}^{\circ} 122$, de 1967 , define:

O hospital é um elemento de Organização de Caráter Médico-Social, cuja função consiste em assegurar Assistência Médica completa, curativa e preventiva à determinada população e cujos serviços externos se irradiam até a célula familiar considerada em seu meio. É um centro de medicina e de pesquisa biossocial (MENDES, 2002).

Portanto, o hospital é uma entidade que tem o comprometimento com a população não só em seu aspecto sanitário curativo e preventivo, mas também em seu aspecto social. Ele se envolve com o homem, em seu meio social, familiar e de relacionamento, 
devendo procurar as causas do desconforto de sua clientela, investigando os casos dos males orgânicos e psíquicos, procurando trazer através da pesquisa científica a solução dos problemas de saúde que afligem a sociedade em que ele está instalado e, de uma maneira mais abrangente, levar os resultados de suas descobertas a todos os continentes do planeta na busca incessante de promover o ser humano (OLIVA; BORBA, 2004).

Segundo Cherubin e Santos (1997), as funções atribuídas a um hospital, ao longo de sua história, vem passando por modificações e tomando uma postura assistencialista com base espiritual e profissionalizando suas atividades. A Comissão de Especialistas da OMS, responsável por elaborar o informe técnico no 122 , fixou as funções como sendo as de prevenir e restaurar as doenças, assim como executar funções educativas e promover pesquisas.

a) Prevenir a doença: a OMS a define como a função mais importante do hospital. Independentemente de porte, localização ou grau hierárquico, o objetivo de um hospital deve ser sempre a manutenção da saúde das pessoas. Todas as disponibilidades humanas, tecnológicas e sua capacidade instalada devem ser mobilizadas para cumprir essa função (CHERUBIN; SANTOS, 1997).

b) Restauração da saúde: é a função mais solicitada pela comunidade, feita através de duas atividades principais: diagnóstico e tratamento. Se essas forem executadas com eficiência e eficácia, o hospital se transforma num dos instrumentos mais benéficos na promoção da saúde. A tarefa do hospital no desempenho dessa sua função será muito facilitada se realizar o diagnóstico e a cura da forma mais precoce possível (LONDOÑO; MORERA; LAVERDE, 2003).

c) Funções educativas: a atividade torna-se diariamente mais complexa, exigindo uma preparação permanente dos profissionais da saúde, para conseguirem utilizar adequadamente os recursos disponíveis. Segundo Cherubin e Santos (1997), todos os hospitais deveriam ser centros docentes em potencial, colocando seus serviços à disposição da formação dos profissionais da saúde de todas as categorias, com todas as unidades devendo sempre ter condições de receber preceptores e estagiários para a prática profissional.

d) Promover a pesquisa: para poder manter e/ou restaurar a saúde, prevenir a doença e exercer funções educativas, o hospital deve ser uma unidade dinâmica e manter-se continuamente atualizado, testando e aplicando constantemente as técnicas e os instrumentos mais atuais descobertos pela ciência.

\subsection{Tipos de organizações hospitalares}

Os hospitais no Brasil podem ser públicos, financiados pelo governo, e particulares, financiados por instituições privadas. Apesar de se diferenciarem pelo tipo de usuário e quantidade de capital investido, ambos possuem a mesma subdivisão, podendo ser gerais ou especializados. Os hospitais gerais, localizados em grandes cidades, também conhecidos como hospitais regionais, abrangem uma área de atendimento maior que o município em que estão localizados. Além do atendimento emergencial, atendem pacientes em todas as patologias, incluindo, necessariamente, as especialidades básicas 
de ginecologia e obstetrícia, pediatria, clínica médica e cirurgia. O hospital geral pode atender a grupos etários específicos, como os hospitais infantis, ou a uma determinada comunidade ou categoria, como o hospital militar. Os hospitais especializados, normalmente implantados em grandes centros, são, na sua maioria, privados, de médio a pequeno porte, e especializados em uma única área da medicina, como, por exemplo, traumatologia/reabilitação, maternidades, hospitais psiquiátricos, etc. (GOES, 2004).

O Ministério da Saúde, com o objetivo de subsidiar os gestores na implantação das políticas de saúde, instituiu o Cadastro Nacional dos Estabelecimentos de Saúde do Brasil (CNES), através da Secretaria de Assistência à Saúde (Portaria no 511/2000), e este cadastro é a base de todos os estabelecimentos de saúde no Brasil. No Rio Grande, temos a seguinte formação, conforme a Tabela 1.

Tabela 1 - Hospitais cadastrados no Rio Grande do Sul

\begin{tabular}{lcc}
\hline HOSPITAIS CADASTRADOS & № & \% \\
\hline Hospital dia & 6 & 1,70 \\
Hospital especializado & 22 & 6,30 \\
Hospital geral & 321 & 92,00 \\
TOTAL & 349 & 100 \\
\hline
\end{tabular}

Fonte: Brasil (2010).

Os estabelecimentos hospitalares gaúchos prestadores de serviços aos SUS são essencialmente formados por hospitais gerais, representam $92 \%$ dos hospitais cadastrados, sendo apenas $6,30 \%$ os hospitais prestadores especializados.

Quanto à natureza administrativa, são classificados como públicos ou privados. Os públicos são mantidos pelo Estado (poder público federal, estadual ou municipal), e os privados são mantidos por recursos oriundos dos pagamentos feitos pelos seus clientes, diretamente ou através de outras fontes provedoras, como seguradoras, cooperativas ou instituições filantrópicas. Geralmente os hospitais privados fazem contratos com o Estado (município, estado ou união) para disponibilizar uma parte de seus leitos para o Sistema Nacional de Saúde.

As instituições sem finalidades lucrativas merecem lugar de destaque na atividade socioeconômica do Brasil. Estas instituições, embora pessoas jurídicas de direito privado, colaboram sobremaneira com os poderes públicos, assumindo inúmeras tarefas, principalmente voltadas às áreas de assistência social, saúde e educação. A qualificação das pessoas jurídicas de direito privado em atividades sem fins lucrativos necessita de adaptação estatutária para compreender os objetivos sociais e para atender aos requisitos impostos pela legislação. Para tanto, não podem distribuir, entre seus sócios ou associados, conselheiros, diretores, empregados ou doadores, eventuais excedentes operacionais, brutos ou líquidos; dividendos, bonificações, participações ou parcelas do seu patrimônio, auferidos mediante o exercício de suas atividades, devendo ainda aplicar integralmente a receita excedente na consecução de seus objetivos sociais (TEIXEIRA, 2008).

Para Teixeira (2008), uma vez que uma entidade sem fins lucrativos cumpra os requisitos estabelecidos, o reconhecimento da imunidade/isenção de tributos passa a 
ser uma obrigação legal do poder público, cujo benefício fiscal somente pode ser revogado por meio de emenda constitucional que altere o respectivo dispositivo. Os requisitos, para que uma instituição usufrua os benefícios da imunidade tributária, são aplicar anualmente $20 \%$ de sua receita total bruta em atendimentos gratuitos à população de baixa renda, ou efetuar atendimentos de, no mínimo, 60\% da capacidade operacional instalada do estabelecimento ao SUS.

Para obter o status de entidade filantrópica beneficente de assistência social pelo Conselho Nacional de Assistência Social, deverá atuar no sentido de:

1) proteger a família, a maternidade, a infância, a adolescência e a velhice;

2) amparar crianças e adolescentes carentes;

3) promover ações de prevenção, habilitação e reabilitação de pessoas portadoras de deficiências;

4) promover, gratuitamente, assistência educacional ou de saúde;

5) promover a integração ao mercado de trabalho; e

6) promover o atendimento e o assessoramento aos beneficiários da Lei Orgânica da Assistência Social e a defesa e garantia dos seus direitos.

A preferência social pelo setor não lucrativo na assistência hospitalar está explicitamente evidenciada na Constituição Federal de 1988 (BRASIL (1988), em seu título da Ordem Social, que, no artigo 199, determina:

§1 - As instituições privadas poderão participar de forma complementar do sistema único de saúde, segundo diretrizes deste, mediante contrato público em convênio, tendo preferência as entidades filantrópicas e as sem fins lucrativos.

§2으 - É vedada, expressamente, a distribuição de recursos públicos para auxílio ou subvenção às instituições privadas com fins lucrativos.

O Cadastro Nacional dos Estabelecimentos de Saúde no Brasil (CNES), permite visualizar a distribuição destas organizações no território brasileiro.

Tabela 2 - Estabelecimentos de saúde no Brasil - setembro de 2010

\begin{tabular}{lcccccccccccc}
\hline $\begin{array}{l}\text { Tipo de } \\
\text { Prestador }\end{array}$ & Norte & $\%$ & Nordeste & $\%$ & Sudeste & $\%$ & Sul & $\%$ & $\begin{array}{c}\text { Centro- } \\
\text { Oeste }\end{array}$ & $\%$ & Total & $\%$ \\
\hline Público & 5.133 & 52 & 22.288 & 48 & 20.652 & 21 & 9.629 & 21 & 4.717 & 24 & 62.419 & 28 \\
$\begin{array}{l}\text { Privados e } \\
\text { Filantrópicos }\end{array}$ & 4.679 & 48 & 23.831 & 52 & 78.503 & 79 & 36.947 & 79 & 14.678 & 76 & 158.638 & 72 \\
Total & 9.812 & 100 & 46.119 & 100 & 99.155 & 100 & 46.576 & 100 & 19.395 & 100 & 221.057 & 100 \\
\hline
\end{tabular}

Fonte: Brasil (2010)

Conforme o CNES, atualmente, no Brasil, os hospitais privados e filantrópicos respondem por $72 \%$ da oferta de serviços de saúde, enquanto que os hospitais públicos respondem por 28\%. Nas regiões Sul, Sudeste e Centro-Oeste, os sistemas privados e filantrópicos são majoritários. 


\subsection{Redes hospitalares}

Segundo Borba (2006), no cenário do mundo globalizado, a informação e os negócios ocorrem de uma forma muito dinâmica, fazendo com que as organizações busquem, cada vez mais, a tecnologia da conectividade, especialmente com o avanço da Internet. Contemporaneamente, o modelo de gestão precisa ser altamente profissionalizado e estratégico, com foco na competitividade, voltado para a modernidade, com espírito de inovar e aprimorar.

Os hospitais, como prestadores de serviço do terceiro setor, estão sujeitos às condições impostas pelo mercado. Como provedores de serviços para o sistema público e privado de saúde, os prestadores estão organizando-se para oferecer serviços de qualidade e a preços mais razoáveis. Uma estratégia é a desospitalização, com o emprego de novos procedimentos em nível ambulatorial, em unidades de rede assistenciais, atendimentos domiciliares (home care), favorecendo a redução da permanência hospitalar e o desenvolvimento da atenção gerenciada, com racionalização da rede de estabelecimentos e de serviços, que envolvem a progressividade do tratamento, incluindo desde a promoção e a prevenção até o tratamento, recuperação da saúde e reabilitação do paciente (BORBA, 2006).

Segundo Borba (2006), os avanços tecnológicos tendem a aumentar os custos da medicina de forma direta, pela sua incorporação às novas rotinas, ou indiretamente, por meio dos repasses dos custos das pesquisas e do desenvolvimento aos consumidores. Algumas tecnologias que aumentam a sensibilidade dos diagnósticos podem aumentar a precisão desses diagnósticos. A engenharia genética e a bioengenharia, por exemplo, estão criando medicamentos e equipamentos sofisticados que aumentam a precisão nos diagnósticos e, com isso, elevam os custos dos procedimentos.

Devido aos elevados custos, as instituições são obrigadas a impor diversas restrições ao acesso às tecnologias. Na prática, acabam sendo encontrados três sistemas: elitista (aberto, amplo e compreensivo, porém de acesso apenas aos privilegiados financeiramente); conveniado (restritivo e com baixa cobertura e acesso controlado aos usuários de convênios ou planos de saúde); e público de saúde (universal, aberto, com ampla e ilimitada cobertura assistencial, mas restrito, pela falta de recursos, para cobrir os custos) com falta de credibilidade junto à população e aos profissionais, que se recusam a trabalhar pelo sistema (BORBA, 2006).

O equilíbrio econômico também pode ser oriundo de investimentos na base, na promoção da saúde, especialmente na coletiva, com prevenção de doenças e promoção de saúde, com métodos e programas coletivos eficazes e com informação e orientação social aos usuários, procurando, com isso, evitar as doenças e atuar diretamente na minimização dos custos assistenciais. Por isso, é essencial a atuação articulada e integrada dos sistemas de informações e inter-relacionamentos que, dessa forma, também pode oferecer subsídios funcionais para desenvolver e implantar um processo amplo e efetivo de Assistência Gerenciada (LONDOÑO; MORERA; LAVERDE, 2003).

Portanto, para o desenvolvimento de uma região, é importante o seu estoque de ativos relacionais, e, neste aspecto, o Sindicato dos Hospitais do Vale do Rio Pardo representa uma alternativa que, embora embrionária, pode ser um importante passo para 
alternativas de atendimento mais racional. Com esta perspectiva, ativa o ciclo virtuoso e movimenta outros seguimentos, não só na assistência hospitalar, mas no comércio, na prestação de serviços, na indústria, etc. A formação de redes hospitalares é uma estratégia já utilizada em alguns países, principalmente para vencer as dificuldades do setor, que possui custos incrementais e orçamento limitado, e, para isso, a rede oferece atenuantes que minimizam o descompasso econômico (CHRISTENSEN, 2009).

\subsection{Redes organizacionais}

Para Vale (2007), embora seja vantajoso aos seus participantes o fortalecimento das organizações com a formação das redes, enfrentam-se muitos desafios para se desencadear um processo de desenvolvimento sustentável que envolva vários municípios. Um dos maiores desafios é a falta de compreensão de especialistas e delineadores de políticas públicas sobre os fatores determinantes deste processo. Esta é uma etapa que precisa ter respaldo técnico, ser desenvolvida por profissionais com capacidade e experiência no ramo, porque dependerá dos laços e das conexões que formam as redes empresariais e territoriais, sendo estes os condicionadores que darão aos seus detentores origem às oportunidades. É o surgimento de um novo ativo de natureza relacional, designado como capital relacional, ou seja, o conjunto de recursos conectados por redes, que garantam acesso às informações que possam gerar oportunidades diferenciadas de acordo com a capacidade do empreendedor em implementá-las.

Para Teixeira (2008), um fator importante é a baixa resolutividade das propostas oferecidas pelo Estado à assistência hospitalar em solucionar os problemas de saúdedoença, impondo limites de acesso e resolutividade dos serviços públicos de saúde. Este é um dos difíceis impasses no seu dia a dia para quem depende do SUS. Tendo em vista que o governo não assume seu papel e responsabilidade de executar e oferecer serviços básicos que atendam, de forma adequada, à demanda e aos problemas enfrentados pela população, as redes são uma das alternativas de enfrentamento para superar os impasses do cotidiano e resistir às condições de precariedade.

As redes interorganizacionais começam a surgir como um importante elemento na busca pela competitividade e na estratégia de sobrevivência das organizações. Este fenômeno acontece devido à cooperação: as organizações conseguem superar limitações e combinar competências de forma sinérgica, obtendo recursos e oportunidades que, individualmente, não conseguiriam. Esta articulação não é discriminatória quanto ao porte de organização, se ela é grande, média ou pequena, pode ser enquadrada em qualquer formato constitutivo, privado, público ou sem fins lucrativos, sendo absolutamente possível a todos que entendem os benefícios da força conjunta (VALE, 2007).

Segundo o autor supracitado, as redes emergem por motivos como redução de custos de transação, aumento no poder de barganha, acesso a novos mercados e recursos escassos. Esses novos arranjos organizacionais são desenvolvidos em resposta a um ambiente dinâmico e competitivo, no qual a base de conhecimentos das organizações é fundamental para gerar inovações e acompanhar as contínuas mudanças ambientais. Em todos os casos, a cooperação é utilizada como uma estratégica capaz de manter, ou ampliar a competitividade dos participantes, diante de um cenário altamente 
competitivo e que muda rapidamente.

A palavra rede é antiga e vem do latim retis, significando o entrelaçamento de fios com aberturas regulares que formam uma espécie de tecido. A palavra tem sido empregada em várias circunstâncias; no início, representava o entrelaçamento de fios; posteriormente, a palavra foi adquirindo novos significados, sendo empregada em outras situações. Mais contemporaneamente, a rede é compreendida dentro de uma estrutura de relações humanas, em que seus integrantes podem estar ligados horizontalmente a todos os demais, diretamente ou através dos que os cercam. Esta estrutura provoca uma série de relações, que se espalham indefinidamente para todos os lados, sem que nenhuma das suas partes possa ser considerada principal ou representante dos demais: a coletividade tem supremacia sobre os interesses individuais (CASTELLS, 2000).

As redes podem ser formais ou informais e apresentarem graus diferentes no seu processo de formalização. As formais possuem contratos, acordos, ou seja, documentação representativa das normas e rotinas que expressem a conduta entre os participantes. Nas redes informais, os participantes estabelecem relações mais estruturadas e frequentes em torno de preocupações semelhantes. São formadas sem qualquer tipo de contrato formal que estabeleça regras, agindo em conformidade com os interesses mútuos de cooperação, baseados principalmente na confiança entre os participantes (MARCON; MOINET, 2001).

Segundo Marcon e Moinet (2001), embora fugindo das formas convencionais, é possível, através de questionários e de técnicas de contextualização oriundas da antropologia organizacional, mapear e compreender, por meio de seus processos de comunicação, como são formadas as estratégicas. O mapeamento das redes informais desvenda dimensões-chave da comunicação organizacional, tais como:

- cooperação - como as informações são dissipadas entre os atores;

- confiança - quem pede conselhos a quem;

- inovação - como as novas descobertas são socializadas;

- motivação - quem são os colaboradores que estimulam e motivam.

Embora sendo uma forma simplificada, se aliada a uma análise da cultura organizacional, é possível diagnosticar os fatores que afetam positiva ou negativamente a cooperação, a inovação e a motivação organizacional.

Os elos gerenciais e o grau de formalidade podem ser uma das formas para distinguir a grande variedade de redes, que podem apresentar estruturas hierárquicas verticais ou horizontais. As redes verticais possuem clara estrutura hierárquica, sendo utilizadas por grandes empresas que formam redes para estarem mais próximas dos clientes. A relação de poder é muito forte, o que se pode equiparar a uma relação da matriz com suas filiais. A participação dos pequenos empreendimentos é de dependência, quase sem influência nas políticas, nas estratégias e nas decisões da rede. Grandes empresas se valem de redes verticais, para garantir flexibilidade na produção, e agilidade, para atender pedidos customizados dos clientes (CASTELLS, 2000).

Nas redes horizontais, segundo Castells (2000), as organizações mantêm sua independência, as atividades são coordenadas de forma conjunta. Com isso, as empresas conseguem inserção em novos mercados, minimização dos custos, maior divulgação dos 
produtos e serviços. Neste formato, as redes se constituem sob a cooperação de todos seus participantes, que possuem poder semelhante. As cooperações existentes nessas relações acabam proporcionando um ambiente de aprendizagem, no qual as relações são complexas, devido aos atores escolherem cooperar dentro de certos limites, pois também podem ser concorrentes. Dessa forma, as redes favorecem a concentração de esforços, sem privar a liberdade de ação estratégica de seus membros.

Segundo Castells (2000), as redes organizacionais são formadas quando são alinhados fatores viabilizadores que motivem seus atores a participar. 0 desempenho dependerá de dois atributos fundamentais: a conectividade, que se refere à capacidade estrutural de facilitar a comunicação sem ruídos entre seus componentes; e a coerência, ou seja, em que medida há interesses compartilhados entre os objetivos da rede e de seus atores.

Para Kelly (1998), quando se quer entender sua essência, percebe-se que a rede é como um organismo descentralizado que não tem limites concretos; não tem centro; não tem cabeça; não há essencialmente algo no comando. As causas não são lineares, e é muito difícil entender os fenômenos que acontecem neste processo. É por isso que existe a ideia de que os controles são muito difíceis quando se tem uma rede.

\section{Regionalização da assistência hospitalar no Vale do Rio Pardo}

As organizações hospitalares, na sua origem, foram formadas para ser soluções de saúde nas suas comunidades. A obrigação de atender a uma região é uma necessidade para a organização sobreviver às novas exigências legais impostas e para sua sustentabilidade. Compreender o processo de regionalização com as suas peculiaridades é uma forma para se achar caminhos com dinâmicas e estratégias que podem contribuir para o desenvolvimento da assistência hospitalar (WEIGELT, 2006).

Segundo Boisier (1999), regiões vistas pelo prisma político-administrativo podem ser conceituadas e mapeadas sem maiores dificuldades. Mas uma região, para que exista efetivamente, precisa ser construída socialmente, a partir de laços comuns, de traços de identidade que se expressam no âmbito do cultural, do econômico e do político, que possibilitem articular desafios comuns à comunidade envolvida. A região é construída socialmente, no momento em que seus integrantes têm consciência dos benefícios, sendo capazes de potencializar sua capacidade de auto-organização, transformando uma sociedade desarticulada, segmentada por interesses setoriais, pouca perceptiva de sua identidade territorial e definitivamente passiva, em outra: organizada, coesa, consciente de sua identidade, capaz de mobilizar-se em torno de projetos políticos comuns, ou seja, capaz de transformar-se em sujeito de seu próprio desenvolvimento.

Além das forças da sociedade organizada, o Estado também precisa fazer sua parte, deve voltar-se para dentro do seu território, visualizar suas potencialidades e promovê-las, não enquanto agente centralizador de decisões, mas enquanto viabilizador do debate, facilitador da capacidade de auto-organização das regiões e, principalmente, enquanto promotor de inserção das regiões no mercado global (BOISIER, 1999).

A região tem também um sentido bastante conhecido como unidade administrativa, e, nesse caso, a divisão regional é o meio pelo qual se exercem, frequente- 
mente, a hierarquia e o controle na administração dos Estados. A formatação da estrutura regional dá-se com definições claras das competências, e os limites são fundamentais para a autonomia dos poderes locais na gestão do território.

Para as organizações hospitalares, a organização do espaço e territorialidades são fatores determinantes no redimensionamento das suas estruturas necessárias para cada região. As necessidades regionais, com suas características, assim como a abrangência do atendimento de cada organização, seriam os fatores determinantes, para definir tipos de hospitais, especialidades médicas necessárias, tecnologias, profissionais de apoio, etc. Ter uma coerência logística, apoiada em análises demográfica, econômica, epidemiológica, são alguns dos fatores determinantes para justificar a existência da estrutura hospitalar.

O estudo da organização espacial parece ser elementar como primeira tarefa na definição das estratégias de gestão organizacional de curto e longo prazo (SANTOS, 2003). Mas, na prática, fica relegado a segundo plano, prevalecendo a demanda de porta, ou seja, o hospital tem como sua região de abrangência os pacientes que buscam atendimento em seu estabelecimento, seja por necessidade, indicação médica, marketing, mas sem uma coerência espacial sistematizada por seus gestores.

Na Região do Vale do Rio Pardo, quando se quer entender a logística hospitalar, encontram-se algumas divergências na formação apresentada pelo Estado - através das Coordenadorias de Saúde, COREDEs e o Sindicato dos Hospitais - pois cada um organiza a região de forma diferente. A falta de sistematização e unidade dos principais organizadores do processo de regionalização hospitalar desencadeia uma série de dificuldades, especialmente para os usuários, que, a rigor, poderão ficar sem assistência, por falta de uma definição concisa de quem efetivamente é o responsável por seu atendimento: quais são os municípios que fazem parte da região? Quem é o responsável pelo atendimento dos procedimentos de média e alta complexidade? Esta é uma perspectiva com estratégias que enfraquece os vínculos, demonstra o espírito individualista imperando sobre o interesse coletivo no enfrentamento de suas dificuldades. Outro fator é a perda da força representativa de classe dos hospitais, que acabam apenas submissos aos ditames das políticas públicas, as quais organizam as regiões conforme seus interesses.

Portanto, as regiões acabam sendo a expressão apenas da visão dos entes públicos de como os espaços devem ser organizados. Segundo Santos (2003), esta é uma metodologia puramente arbitrária, que não considera as características regionais que possibilitariam vínculos de interesse comum, não permite o desenvolvimento de redes que poderiam pactuar convênios reciprocamente vantajosos (VALE, 2007).

A organização espacial dos hospitais no Vale do Rio Pardo não possui unidade quanto à definição das regiões, assumindo formatos diferentes, com interpretações divergentes quanto às potencialidades locais. Na região do Vale do Rio Pardo, têm-se importantes organizações hospitalares com um grau de complexidade de hospital geral, as quais por suas pesadas estruturas precisam atender a regiões que estejam bem definidas e que possam custear a disponibilidades de leitos ofertados para esta região. Segundo Christensen (2009), a falta de uma definição precisa das regiões pode estimular a concorrência entre as organizações, com pulverização desnecessária de investimento. 
O processo de organização dos hospitais em seus territórios, seja pelo Estado, com as Coordenadorias Regionais de Saúde, COREDEs ou sindicato dos hospitais, apresenta formações diferentes. Exceto o sindicato, as outras formações representam modelos de divisão pré-estabelecida, definida apenas conforme a visão dos entes públicos (SANTOS, 2003). Apenas os municípios identificados na cor vermelha representam a intersecção, onde todos pertencem à mesma denominação territorial, ou seja, dos 28 municípios abrangidos pelos três atores, apenas dez pertencem igualmente ao mesmo sindicato, coordenadoria de saúde e COREDE.

\section{llustração 1 - Regionalização do COREDE/VRP, SINDHVARP e 8a e 13ạ CRS}

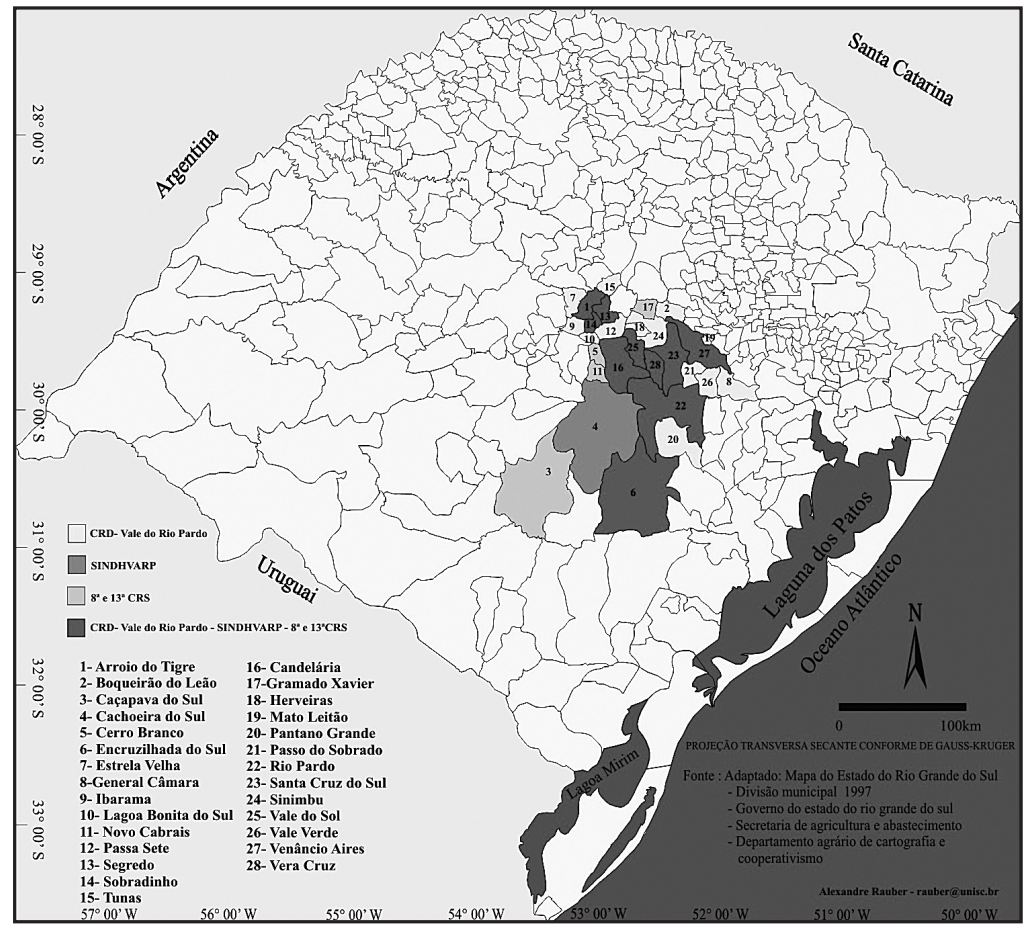

Fonte: Laboratório de Geoprocessamento da Unisc (2014).

Nos sistemas de saúde regionalizados, o maior desafio está em buscar a integralidade da atenção aos cidadãos pertencentes àquele espaço delimitado (MENDES, 2002). Nesse sentido, a saúde tomada em sua complexidade e como manifestação da vida encontra no território seu espaço de realização. Nas palavras de Santos (1999, p. 5), o território representa:

O conjunto de sistemas naturais mais os acréscimos históricos materiais impostos pelo homem. Ele seria formado pelo conjunto indissociável do substrato físico, natural ou artificial, e mais o seu uso, ou, em outras palavras, a base técnica e mais as práticas sociais, isto é, uma combinação de técnica e de política. Os acréscimos são destinados a permitir, em cada época, uma nova modernização, que é sempre seletiva. 
Nesse contexto, o sindicato representa uma alternativa de superação da fragmentação e da falta de coordenação nos sistemas de saúde, sendo este um dos grandes desafios a ser enfrentado pelos gestores. As estratégias e mecanismos voltados à descentralização têm se aproximado, em diferentes graus, de um modelo de saúde voltado à integralidade. A organização de sistemas com redes organizadas, segundo diferentes densidades tecnológicas e acessadas conforme as necessidades de saúde da população, que se baseiem nos conhecimentos de planejamento, de epidemiologia e das ciências sociais, tem sido um desafio no cenário da descentralização e municipalização da saúde.

A saúde é uma arena com diferentes atores, na qual o interesse comum é algo questionável, porque os indivíduos, dentre suas especificidades, têm algumas prioridades que se sobressaem em função das condições circunstanciais do momento em que se encontram. Diante disso, entende-se a permanente conflitualidade dessas relações, emergindo aí a necessidade de utilização de estratégias, para lidar com essas diferenças, ou, em outras palavras, coordená-las em busca de benefícios coletivos, pautados na legislação da saúde, que prioriza a regionalização com enfoque de equidade, universalidade e integralidade da atenção.

Segundo Weigelt (2006), como grande solução para a maioria dos problemas dos municípios aparece, em alguns discursos, a regionalização da saúde, uma vez que quase a totalidade dos municípios desta região não consegue atender a suas demandas de assistência à população, principalmente no que se refere aos atendimentos de média complexidade, alegando a falta de recursos financeiros, humanos, materiais e de equipamentos.

O desenvolvimento da atividade hospitalar depende da dinâmica racional que seus atores conseguem implementar na regionalização da assistência. Para tanto, duas estratégias vêm à tona: uma se refere à harmonização da prestação de serviços entre órgãos de saúde situados em diferentes níveis, por sua complexidade, problemas econômicos e recursos tecnológicos; a outra estratégia consiste na associação, aliança ou constituição de redes horizontais entre instituições de igual nível ou de níveis diferentes, situadas em diferentes municípios, localidades ou áreas geográficas, para fortalecer as instituições hospitalares e apresentá-las como uma frente solidária perante órgãos que queiram contratar seus serviços.

\section{A regionalização e as redes organizacionais na visão dos gestores hospitalares do SINDHVARP}

Esta seção apresenta a visão dos gestores hospitalares sobre a interação das instituições com o sindicato dos hospitais, as dificuldades e oportunidades com a participação, assim como a regionalização da assistência hospitalar, relacionando-as com as dinâmicas utilizadas nas redes organizacionais, identificando-lhes as dificuldades e os benefícios aos seus participantes, especialmente para os hospitais que fazem parte do SINDHVARP. O objetivo foi identificar, com as experiências relatadas pelos seus gestores, questões práticas que validam ou invalidam os benefícios apresentados pela literatura sobre as redes hospitalares.

Para este estudo, foi utilizada a metodologia descritivo-exploratória, com abor- 
dagem qualitativa, para avaliação dos casos abordados. A técnica escolhida foi a da entrevista semiestruturada, com respostas abertas, que seguiram um roteiro previamente estabelecido, cujo objetivo foi o de ordenar o diálogo e o pensamento, tanto do pesquisador quanto do interlocutor (YIN, 2001).

As entrevistas foram realizadas com os responsáveis pela gestão dos dois hospitais regionais, em que se teve a oportunidade de entrevistar o presidente da Associação dos Hospitais Filantrópicos, o presidente da Federação dos Hospitais do Rio Grande Sul, a secretária de Saúde da Microrregião de Sobradinho e diretores de dois hospitais microrregionais. Todos os gestores hospitalares entrevistados fazem parte da Associação dos Hospitais do Vale do Rio Pardo. Também, de forma complementar, entrevistou-se o consultor Internacional da Associação Beneficente de Assistência Social e Hospitalar Pró-Saúde de São Paulo e o presidente do COREDE, Jacuí Centro. As entrevistas foram gravadas com a autorização prévia dos entrevistados, o que facilitou o diálogo e a análise das informações, cuja transcrição foi viabilizada na íntegra.

Nas respostas, os gestores hospitalares demonstram uma unidade de pensamento quanto à dificuldade para continuar atendendo ao SUS, que atualmente é o maior comprador dos serviços hospitalares da região. A falta de unidade dos participantes é uma das dificuldades para ampliar as estratégias da associação. Sem contar com auxílio do poder público, apenas com a ajuda de suas comunidades locais, cada um, isoladamente, acaba fazendo pesados investimentos, para permanecer de forma competitiva ofertando serviços à população local, na tentativa de captar o maior número possível de pacientes dada sua estrutura e sua capacidade de atendimento.

Os gestores hospitalares demonstraram certo desconhecimento das possibilidades oferecidas pelas dinâmicas das redes organizacionais, ficando quase todas as respostas restritas à central de compras. Mas todos reconhecem a importância da associação, principalmente na defesa de duas questões vitais para os hospitais: negociações de salários e tabelas dos convênios, que parecem ser as estratégias do sindicato, que não possui estrutura própria para operacionalizar outras atividades.

A sustentabilidade é o principal problema apontado pelos gestores, que é agravado pela disposição dos agentes públicos em criar obrigações sem contrapartida financeira. Com valores defasados e insuficientes para cobrir os custos, profissionais e instituições perdem o interesse pelo SUS, limitando o atendimento apenas para cumprir tão somente a exigência legal mínima de $60 \%$ do atendimento para a manutenção da filantropia e sua consequente isenção fiscal. Como os hospitais possuem custos que são incrementais e uma demanda sempre crescente, o estrangulamento das tabelas é a estratégia utilizada pelos governantes para manter/limitar a produção dos serviços hospitalares, que são insuficientes frente à demanda, ocasionando filas de espera pelo atendimento e para os procedimentos.

Os hospitais que pertencem ao sindicato são empresas privadas, cuja sobrevivência e desenvolvimento dos serviços dependem unicamente de sua atividade. Deixar de atender pacientes particulares não é uma lógica para este segmento, pois eles são necessários para compensar a perda de receita/prejuízo com o atendimento ao SUS, mas, ao mesmo tempo, à medida que cresce o atendimento a particulares, precisa aumentar o atendimento via SUS, para a manutenção da filantropia, como foi afirmado 
anteriormente. Da mesma forma, ao mesmo tempo em que a correção das tabelas do SUS, nos patamares julgados pelas organizações hospitalares como sendo necessária, não só se elevariam os gastos do poder público com a estrutura de oferta atual, como seria difícil conseguir fazer frente à elevação de gastos, num segundo momento, quando os hospitais começassem a atender à demanda reprimida do SUS - dado que, com o reajuste da tabela, a elevação da oferta de exames/procedimentos se tornaria atrativa às organizações.

Conforme comentado anteriormente, enfrentar dificuldades financeiras parece ser uma realidade histórica dos hospitais filantrópicos: quando estão agonizando, o poder público acaba tendo que agir, ou assumir sua obrigação, que fora delegada, resolvendo pontualmente algumas calamidades, com uma política intervencionista e não planejada. Tão logo a situação financeira se estabilize, o poder público retira seu apoio, e se inicia um novo ciclo de acúmulo de déficits que leva, mais à frente, à nova necessidade de apoio/intervenção pública.

As estratégias das redes, além de não serem conhecidas de forma aprofundada pelos gestores, encontrariam, nas comunidades, a resistência do novo; os proprietários dos hospitais, que com sacrifício construíram e tentam manter o patrimônio, com a rede, teriam que abrir mão, ou partilhar com outros donos, e este cenário desconhecido coloca as comunidades com o falso sentimento de perda de sua instituição.

A regionalização da saúde é bem-vista por todos os entrevistados, que entendem que ela é uma excelente estratégia, porém regionalizar o SUS ninguém quer, principalmente porque a saúde é municipalizada, e os valores complementares que as prefeituras pagam para algumas especialidades é para atender a seus munícipes. Outro fator é a desorganização das regiões, sendo esta mais uma barreira para pactuarem ações conjuntas.

As entrevistas realizadas foram oportunidades de aprendizagem sobre o tema; pela riqueza de informações, pôde-se compreender melhor a realidade e as dificuldades vivenciadas pelos diretores hospitalares, que já acumulam longos anos na coordenação dessas organizações. Todos os gestores possuíam formação ou especialização na área, o que possuía menos tempo de experiência já estava há cinco anos na função, e o que possuía mais tempo já estava há 21 anos como gestor da organização.

\section{Considerações finais}

Os hospitais, a partir do século XV, foram considerados comunitários e indispensáveis, época também em que houve o envolvimento dos entes públicos como responsáveis pelo problema. Até então, as instituições contavam com o auxílio de suas comunidades, que faziam o que era possível para atender aos segregados da época. Contemporaneamente, no Brasil, as precariedades dessas organizações continuam, especialmente porque ainda não são aplicados, pelo poder público, os percentuais legais na saúde. Com orçamentos apertados, há permanentes conflitos entre os técnicos que estão na linha de frente, principalmente nas redes básicas, com as emergências e urgências hospitalares.

As tabelas do SUS, consideradas defasadas pelos gestores, não são sustentáveis 
e, em algumas situações, podem inviabilizar as instituições. Em contrapartida, as tabelas julgadas coerentes pelas instituições, para prestarem um serviço de qualidade para o SUS, seguramente estimulariam a internação e aumentariam sobremaneira as despesas do sistema, uma vez que possuem uma demanda reprimida. Em nossa análise, deveria ser revista a forma de financiamento, que hoje remunera pela doença (o atendimento e os exames e procedimentos decorrentes): os hospitais, após apresentarem suas faturas, recebem os valores que atualmente dizem ser insuficientes. A não correção das tabelas não é por desconhecimento do poder público, mas sim porque, se as corrigir, não terá como bancá-las.

Sobre as estratégias utilizadas nas redes organizacionais e a regionalização, embora todos os entrevistados reconheçam seus benefícios, na prática, todos teriam resistência de regionalizar o atendimento para o SUS. A regionalização já foi definida pelo estado e, no campo filosófico, está razoavelmente bem elaborada. Como a saúde está municipalizada, os municípios bancam o prejuízo do SUS, especialmente com os profissionais médicos, apenas para seus munícipes, mas não conseguem atender à região sem complementação das tabelas.

A estratégias de redes organizacionais e de prevenção são atividades que poderiam ser desenvolvidas pelo hospital e que reduziriam expressivamente os gastos com saúde. Outra função importante seria a pesquisa, pois os dados epidemiológicos são informações estatísticas à disposição dos hospitais, uma informação valiosa para desenvolverem pesquisas em todos os tipos de prevenção, orientação e conscientização da sociedade, seria uma ferramenta para se evoluir na redução e prevenção de doenças.

Além de corrigir as tabelas atuais, o SUS, buscando o desenvolvimento regional da assistência hospitalar, poderia remunerar os prestadores com valores fixos e por região, não remunerar os serviços por produtividade (atendimentos, exames, procedimentos), mas com um novo formato, voltado para prevenção e pesquisa. Recebendo um valor fixo por orçamento, o hospital passaria de adversário para parceiro da rede básica, porque o ganho estaria em não internar. Outra motivação é a possibilidade de trabalhar a assistência hospitalar de forma complementar, tornar-se especialista e no formato de rede, reduzindo os custos e aumentando a rentabilidade, mas, principalmente, ganhando em qualidade de vida para a população.

A remuneração fixa por orçamento teria sua regulamentação direcionando incentivos, especialmente para pesquisa e prevenção, tema que precisará uma nova pesquisa complementar, mas que, pelas evidências até o momento, parece ser o caminho mais motivador para o desenvolvimento, não apenas dos hospitais, mas do sistema como um todo. Seria uma forma do poder público descentralizar, partilhar as responsabilidades, envolvendo os técnicos da área, com a missão de serem criativos para fazer das regiões centros resolutivos.

\section{Referências}

ANTUNES, J. L. F. Hospital: instituição e história social. São Paulo: Letras e Letras, 1991.

BOISIER, S. Teorias y metáforas sobre desarrollo territorial. Santiago de Chile: CEPAL, Naciones Unidas, 1999. 
BORBA, V. R. Do Planejamento ao Controle de Gestão Hospitalar. Rio de Janeiro: Qualitymark, 2006.

BRASIL. Ministério da Saúde. Anuário Estatístico da Saúde do Brasil - 2001. Recursos Físicos. 2001. Brasília. Disponível em: <http://portal.saude.gov.br/saude/aplicaçoes/ anuario2001/index.cfm>. Acesso em: 10 ago. 2014.

. Ministério da Saúde. Cadastro Nacional dos Estabelecimentos de Saúde no Brasil (CNES), 2010. Brasília. Disponível em: <http://portal.saude.gov.br/saude/>. Acesso em: 10 out. 2014.

. Presidência da República. Constituição Federal da República. 1988. Disponível em: <http://www.planalto.gov.br/ccivil_03/constituicao/constituicaocompilado.htm>. Acesso em: 10 ago. 2014.

CARVALHO, M. C. B. Avaliação Participativa: uma escolha metodológica. São Paulo: Cortez, 1999.

CASTELLS, M. A sociedade em Rede: a era da informação: economia, sociedade e cultura. São Paulo: Paz e Terra, 2000.

CHERUBIN, N. A.; SANTOS, N. A. Administração Hospitalar: fundamentos. São Paulo: Cedas, 1997.

CHRISTENSEN, C. M. Inovação na Gestão da Saúde. São Paulo: Artmed, 2009.

GOES, R. Manual prático da Arquitetura Hospitalar. São Paulo. Edgard Blucher, 2004.

KELLY, K. A nova biologia dos negócios. In: GIBSON, R. Repensando o futuro. São Paulo: MAKRON Books, 1998.

LONDOÑO, M; MORERA, G; LAVERDE, P. Administração Hospitalar. 2. ed. Rio de Janeiro: Guanabara, 2003.

MACHADO, R. A medicina social e constituição da psiquiatria no Brasil. Rio de Janeiro: Graal, 1978.

MARCON, C.; MOINET, N. Estratégia - Rede. Caxias do Sul: Educs, 2001.

MENDES, E. V. Os sistemas de serviços de saúde: o que os gestores deveriam saber sobre essas organizações complexas. Fortaleza: Escola de Saúde Pública do Ceará, 2002.

MIRSHAWKA, V. Hospital: fui bem atendido. São Paulo: Makron Books, 1994.

OLIVA, F. A; BORBA, V. R. Balanced Scorecard, Ferramentas Gerenciais para Organizações Hospitalares. São Paulo: Látria, 2004.

PAIM, J. S.; ALMEIDA, F. N. A crise da saúde pública e a utopia da saúde coletiva. Salvador: Casa da Qualidade, 2000.

RIVERA, F. J. U. Análise Estratégica em Saúde e Gestão pela Escuta. Rio de Janeiro: FIOCRUZ, 2003. 
SANTOS, M. Guerra dos Lugares. Áreas inteiras do Brasil têm sido retiradas do controle do país. Especial para a Folha. Publicado em 8 set. 99, caderno Mais! Folha de São Paulo: São Paulo, 1999.

SANTOS, M. Economia Espacial: críticas e alternativas. 2. ed. São Paulo: Edusp, 2003.

TEIXEIRA, J. Assuntos Hospitalares na Visão Jurídica. São Paulo: Pró-Saúde, 2008.

UNIVERSIDADE DE SANTA CRUZ DO SUL. Laboratório de Geoprocessamento da Unisc. Regionalização do COREDE/VRP, SINDHVARP e 8a e 13ㅁ CRS. Santa Cruz do Sul: Unisc, 2014.

VALE, G. M. V. Territórios vitoriosos: o papel das redes organizacionais. Rio de Janeiro: Garamond, 2007.

WEIGELT, L. D. Política Pública de Saúde: um estudo sobre o processo de implementação da descentralização/regionalização da saúde na região do Vale do Rio Pardo - RS.

Tese (Doutorado em Desenvolvimento Regional) - Universidade de Santa Cruz do Sul, Santa Cruz do Sul 2006.

YIN, R. K. Estudo de caso: planejamento e métodos. Porto Alegre: Bookman, 2001. 